Perspectiva Geográfica

ISSN 0123-3769

Vol. 15/2010; pp. 9-36

\title{
Corredores y territorios estratégicos del conflicto armado colombiano: una prioridad por territorializar en la geopolítica de los actores armados
}

Strategic corridors and territories in the colombian armed conflict: a priority for territorializing for the geopolitics

of the armed actors

Luis Gabriel Salas Salazar*

\section{Resumen}

Los recientes estudios e investigaciones del conflicto armado en Colombia han hecho referencia a la posible existencia de corredores y territorios estratégicos; no obstante, no han ofrecido evidencias concretas de su existencia, ni mucho menos han logrado caracterizar su territorialidad. El trabajo investigativo que aquí se presenta tuvo como objetivo analizar e interpretar la dinámica de las territorialidades de los corredores y territorios estratégicos de los actores del conflicto armado colombiano, en el periodo 1990 2009, desde una perspectiva de la Geografía Política. Las evidencias empíricas de esta investigación permiten establecer que la dinámica de las territorialidades de estos espacios estratégicos del conflicto armado colombiano se ha desplegado a través de tres niveles: en el nacional, en el regional y en el subregional local. Para cada uno de ellos existe una dinámica territorial, en donde los actores armados han configurando una condición multiescalar de las territorialidades de los corredores y territorios geoestratégicos en Colombia.

Palabras clave: Colombia, Conflicto Armado, Corredores Estratégicos, Geopolítica, Territorios estratégicos.

* Magíster en Geografía, UPTC-IGAC, docente universitario. luisgeo01@yahoo.com; Igsalass@unal.edu.co El autor agradece la asesoría del Doctor en Geografía Gustavo Montañez Gómez. 


\begin{abstract}
Recent studies and investigations of the armed conflict in Colombia have made reference to the possible existence of corridors and strategic territories. However, have not offered concrete evidence of their existence; much less have they managed to characterize its territoriality. This research work's aim is to analyze and interpret the dynamics of the corridors' territories, as well as the Colombian armed actors' strategic areas during the period of 1990 2009, from the Political Geography perspective. Empirical evidence from this research allows us to establish that the dynamics of the territoriality of these strategic areas of the armed conflict in Colombia, have been deployed across three levels: national, regional and local sub regional. For each, there is a regional process, where armed groups have been setting up a multi scale status of the corridors' territories and geo strategic areas in Colombia.
\end{abstract}

Keywords: Armed Conflict, Strategic Corridors, Colombia, Geopolitical, Strategic territory.

I 0 Luis Gabriel Salas Salazar 


\section{Introducción}

Este documento analiza e interpreta, desde la perspectiva de la Geografía Política, la dinámica de las territorialidades de los corredores y territorios estratégicos de los actores del conflicto armado colombiano, en el periodo 1990-2009; surge de la reflexión sobre estudios recientes de este conflicto, los cuales, en general, hacen referencia a la existencia de los corredores y territorios estratégicos como un componente determinante de su dinámica, sin ofrecer una caracterización clara y consistente de ellos, ni brindar evidencias cartográficas reales de su existencia.

A través de la revisión del estado del arte de las investigaciones y concepciones que abordan el estudio del conflicto armado colombiano en general -por un lado, la postura de los "violentólogos", y, por el otro, la postura de los economistas- se ha identificado que no han incorporado de manera deliberada y pertinente una perspectiva geográfica, que no se han considerado las dimensiones territoriales del conflicto como un elemento importante para su explicación. De hecho, "las aproximaciones de tipo geográfico, en particular las representaciones cartográficas, fueron relativamente escasas hasta una fecha reciente, cuando, paradójicamente, la dinámica propiamente territorial de los hechos sociopolíticos y de los actores involucrados aparecía, de golpe, como una evidencia para todos los investigadores que han abordado el tema" (Pissoa y Gouëset, 2002). Más aún, los trabajos y estudios relacionados con la dimensión subnacional de la Geografía Política son muy escasos, casi inexistentes (McColl, 1969).

Para el desarrollo de esta investigación se consideran dos soportes teóricos fundamentales planteados desde la Geografía: territorio y territorialidad. Para Bozzano (2000), el territorio o espacio geográfico es un lugar donde se desarrollan procesos naturales y donde se despliegan procesos sociales, cuya combinación lo torna más complejo que cualquier visión analítica profunda de sus componentes; en este contexto, el territorio no es solo la suma y combinación de formas espaciales y procesos sociales, no es la naturaleza ni la sociedad, ni su articulación, sino naturaleza, sociedad y articulaciones juntas, y por ello en cada particularidad el territorio adquirirá una espacialidad particular. De otro lado, Sack (1986) define la territorialidad a partir de dos dimensiones: el carácter histórico de la territorialidad y su relación con el poder, $\mathrm{y}$, en este último sentido, la considera como una conducta de actores que intentan influir, afectar o controlar, con ciertas acciones, un territorio particular. También puede ser considerada la territorialidad como "el grado de control de una determinada porción de espacio geográfico por una persona, un grupo social, un grupo étnico, una compañía multinacional, un Estado o un bloque de Estado" (Montañez et al., 1997).

En esta investigación se pudo establecer que la dinámica de las territorialidades 
de los corredores y territorios estratégicos del conflicto armado colombiano se ha desplegado a través de tres niveles: en el nacional, en el regional y en el subregional-local; para cada uno de ellos existe una dinámica territorial en donde los actores armados del conflicto han desplegado sus operaciones militares, económicas y políticas, configurando una condición multiescalar de las territorialidades de los corredores y territorios estratégicos. Cuando las vocaciones de control y de poder de los actores del conflicto armado se debilitan en el nivel nacional, la disputa por el control territorial de los corredores y territorios estratégicos se hace más interna en los niveles regionales y subregional-locales.

\section{Metodología}

La propuesta metodológica que se definió para este trabajo se caracterizó por ser mixta: involucró técnicas de investigación cuantitativa y cualitativa. Primero se realizó el análisis territorial del conflicto armado nacional y su especialidad, y posteriormente se identificó la estrategia territorial del conflicto armado en la región del Suroccidente colombiano; esto al considerar que la territorialidad de los corredores y territorios estratégicos registra una dinámica multiescalar, por lo tanto, se consideró la región del Suroccidente colombiano como un estudio de caso para corroborar esta afirmación.

A la información disponible en bases de datos sobre la violencia y el conflicto armado colombiano y la región del Suroccidente colombiano, para las dos décadas consideradas, se le realizó un análisis cuantitativo basado en la estadística descriptiva. Para el análisis espacial del conflicto armado colombiano se consideró el municipio como unidad de análisis, aplicando métodos geoestadísticos que permitieron la elaboración cartográfica basados en la implementación del método de interpolación de densidades focales kernel, el método de interpolación Krigin Natural Neighbor (Salas, 2007) y el uso de álgebra de mapas.

Para el análisis regional-local realizado en el Suroccidente colombiano, la georreferenciación de los datos alfanuméricos del conflicto y la violencia se hizo a través de la definición de las coordenadas del lugar aproximado del hecho, a través de la lectura de la información del contexto del registro de eventos del conflicto armado, la cual suministró la fuente primaria con la que fue posible inferir lugares o hitos, que se encontraron en la toponimia de la cartografía básica 1:100.000 que suministró el Instituto Geográfico Agustín Codazzi de Colombia -IGAC-; por lo tanto, la unidad de análisis para la interpretación espacial del conflicto armado de la región del Suroccidente colombiano fue el lugar del hecho.

Tanto la información cualitativa como la cuantitativa del conflicto armado nacional y regional fue analizada y procesada, lo que permitió identificar la dinámica del conflicto armado, los corredores y

I 2 Luis Gabriel Salas Salazar 
territorios estratégicos colombianos en disputa por su control, registrada en las dos décadas (1990-2009). Para mayor detalle de la metodología de esta investigación, ver Salas (2010).

\section{Fuentes de datos alfanuméricos y cartográficos}

Se consideraron los datos agregados a nivel municipal, disponibles en el Sistema Público de Información de Derechos Humanos y Derecho Internacional Humanitario, del Observatorio del Programa Presidencial de Derechos Humanos y Derecho Internacional Humanitario de la Vicepresidencia de la República de Colombia para el periodo 1990-2009.

En cuanto a la información cartográfica, se consideraron las bases geográficas digitales del IGAC en coordenadas geográficas, con un sistema de proyección conforme a Gauss y tomando como referencia el elipsoide internacional. Dentro de ello se consideró la cartografía digital integrada de Colombia, a escala 1:500.000, para el análisis nacional y cuya unidad básica de estudio fue el municipio. Para el análisis regional, cuya unidad de análisis fue el lugar aproximado del evento del conflicto armado, se consideró la cartografía digital de la región, considerada a escala 1:100.000. Así mismo, se consideraron las áreas de cultivos ilícitos reportadas por el Sistema de Monitoreo de Cultivos Ilícitos, del Programa de las Naciones Unidas Contra las Drogas y el Delito en Colombia -SIMCI-, desde el año 2000 hasta el año 2008.

\section{Resultados}

\subsection{Cambios evidentes en la dinámica espacial del conflicto armado colombiano, 1990-2009}

Los fenómenos de guerra o de violencia en Colombia no datan de las últimas décadas; desde la independencia constituyen gran parte de la historia de este país. En el siglo XIX, cerca de veinte guerras regionales o nacionales enfrentaron a los partidos Conservador y Liberal; la última de estas guerras civiles, llamada Guerra de los Mil Días, duró desde 1899 a 1902, causó aproximadamente cien mil víctimas (contando las indirectas por enfermedades), en una población de menos de tres millones de habitantes, y terminó con la separación de Panamá (Pécaut, 2008). Sobrevino entonces un periodo de calma, pero en 1946 comienza una nueva guerra civil entre los dos partidos políticos tradicionales (liberales y conservadores), que solo termina hacia 1962; guerra conocida con el nombre de La Violencia, que fue particularmente atroz; el actual conflicto se enlaza inmediatamente con ella. A estas guerras políticas hay que agregar los enfrentamientos sociales, a menudo sangrientos (Pécaut, 2008). La Figura 1 ilustra claramente la evolución de la tasa nacional de homicidios entre los años 1946 y 2009; para facilitar su interpretación se han asociado cuatro periodos sociales y políticos de la vida nacional (ver Figura 1), que ayudan a comprender el comportamiento dinámico de la violencia en Colombia. 


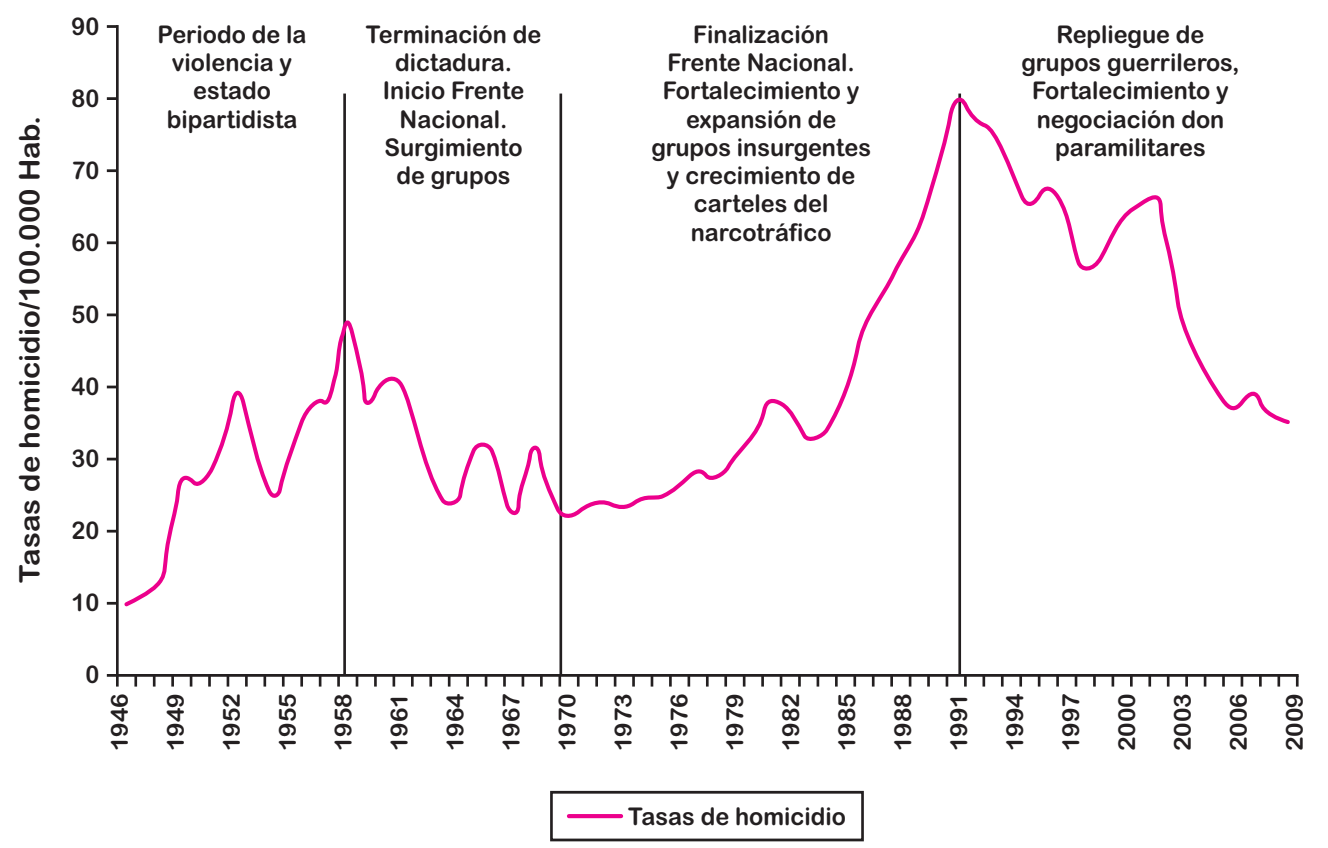

Figura 1. Evolución de la tasa nacional de homicidios, 1946-2009

Fuente: Policía Nacional. Procesado y elaborado por el autor.

Por tratarse en esta investigación de identificar los cambios de la dinámica espacial en Colombia desde 1990 hasta 2009, se hará énfasis en contextualizar este último periodo (1990-2009). El periodo que antecede a la década de los noventa en Colombia se caracterizó por un incremento vertiginoso de la violencia (1982-1990), asociado al surgimiento en firme del narcotráfico y a la guerra entre los llamados carteles de la droga (de Cali y de Medellín) y el Estado, registrándose niveles críticos de violencia en departamentos como Antioquia y Valle, especialmente en sus capitales, Medellín y Cali, y en otras ciudades, como Pereira.
De 1992 a 1998, inscrito en este reciente periodo de la violencia en Colombia (Gráfica 1), se observa un descenso en la tasa de homicidios, pero con niveles altos, que coinciden, grosso modo, con que personajes del Cartel de Medellín, como Gonzalo Rodríguez Gacha y Pablo Escobar, fueron dados de baja, y disminuyeran las muertes ocasionadas por el narcoterrorismo; igualmente, coincide con un debilitamiento de las agrupaciones paramilitares impulsadas por el cartel de Medellín; algunas agrupaciones, incluso, se sometieron a la justicia. Por otra parte, para esta época las guerrillas de las FARC y el ELN ya se habían fortalecido significativamente,

14 Luis Gabriel Salas Salazar 
a tal punto que se expandieron por gran parte de la geografía del país.

Desde el periodo presidencial de Andrés Pastrana (1998-2002), las Fuerzas Militares experimentan un periodo de modernización y transformación, que se traduce en una ventaja en el combate con los grupos guerrilleros y narcotraficantes. El porcentaje de presupuesto destinado a los gastos militares aumenta cada año, hasta alcanzar uno de los niveles más altos del mundo, lo que se traduce en el número de efectivos y en la dotación de armamentos de última generación, que evidencia una mejora en la cobertura del territorio por parte de la
Fuerza Pública, y progresa la calidad de la información en inteligencia (Pécaut, 2008), como se puede interpretar en la Figura 2.

La afectación espacial de la intensidad del conflicto armado es muy focalizada en la geografía nacional (Figura 3); se evidencian en general niveles altos de conflicto armado en sectores de la región norte del país, en Arauca, en la región del Catatumbo (en Norte de Santander), el Magdalena Medio y el Urabá antioqueño. A partir del 2002 se redefine el conflicto armado reciente y se expresa en un incremento en los homicidios en el conjunto de la nación, tal y como se

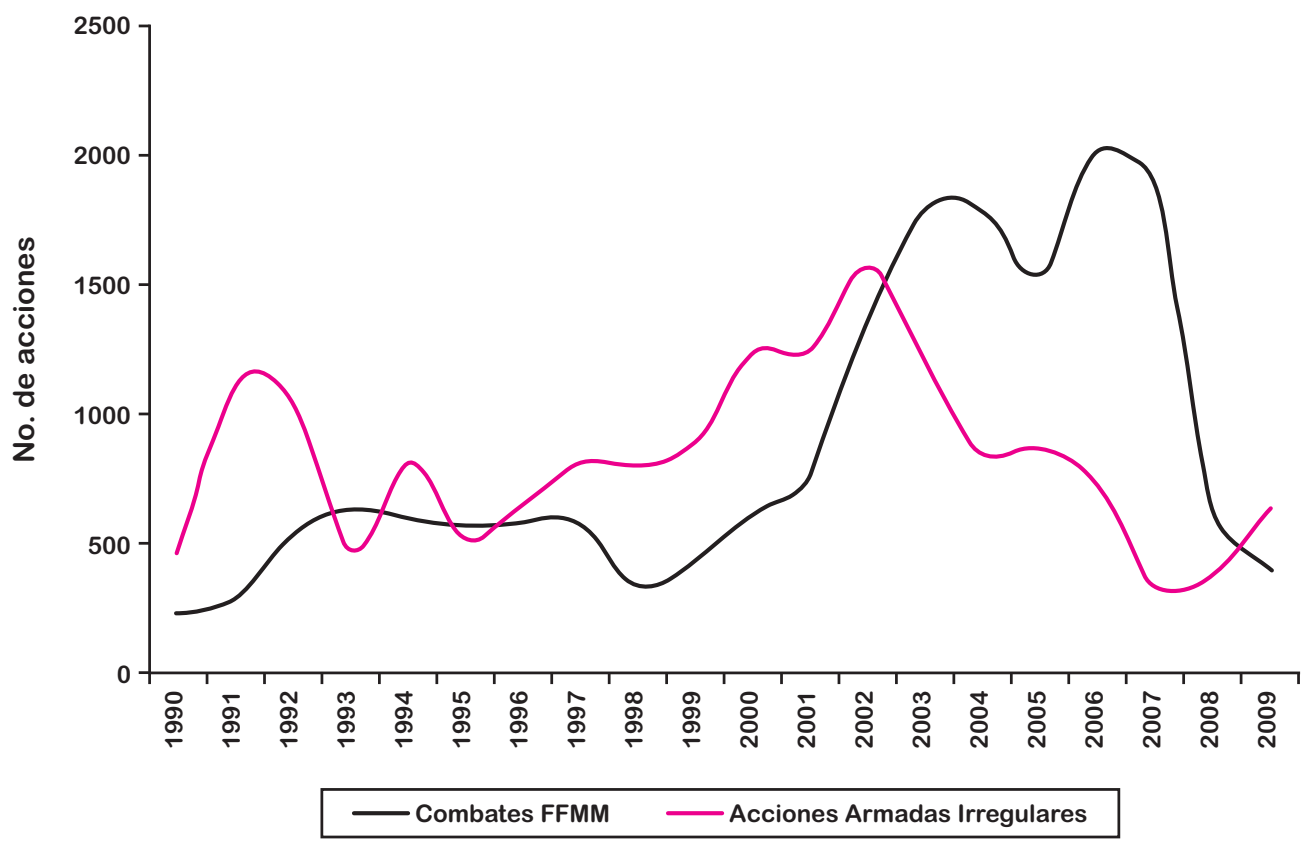

Figura 2. Evolución de las acciones armadas de los grupos irregulares, y de los combates por iniciativa de la Fuerza Pública en su contra en Colombia. 1990 - 2009

Fuente: DAS. Procesado y elaborado por el autor. 
aprecia en la Figura 1. Finalizada la Zona de Distensión e iniciado el gobierno de Álvaro Uribe, en el año de 2002, con su manifiesto por arremeter militarmente contra los irregulares, e iniciar un proceso de Paz con las Autodefensas, hace que la guerrilla de las FARC, en particular, pierdan paulatinamente la iniciativa de la confrontación (ver Figura 2). Bajo este panorama, las FARC cambian en su estrategia armada, dando paso a un aumento en los actos terroristas, para poder enfrentar a la Fuerza Pública y de esta manera evitar la confrontación directa, evitando una posible derrota militar (Echandía, 2006).

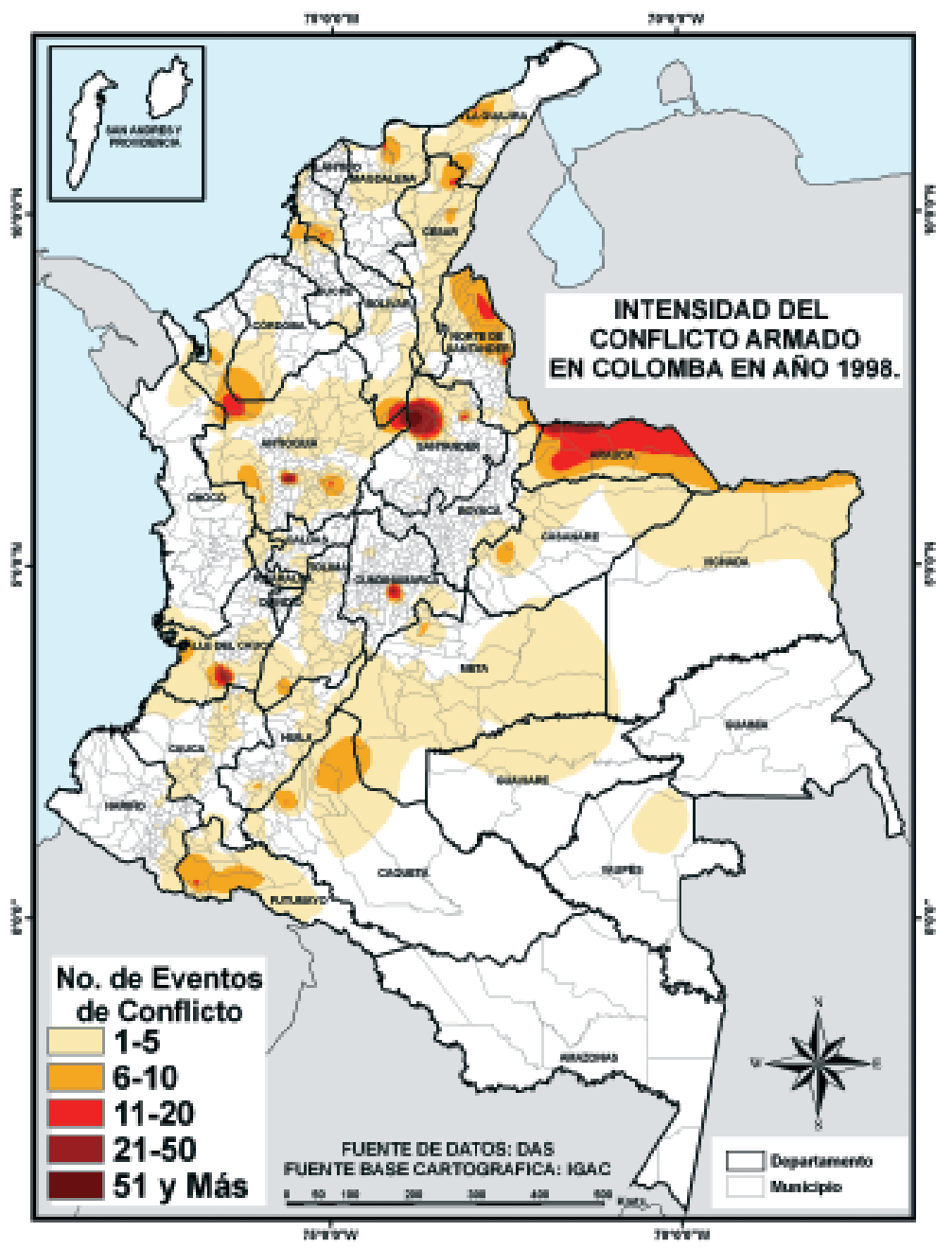

Figura 3. Intensidad del conflicto armado en Colombia, 1998

Fuente: Procesado y elaborado por el autor. 
El gobierno de Uribe dio inicio a su Política se Seguridad Democrática, siendo el corazón de ésta la acción militar en contra de las FARC. Como consecuencia de ello, las FARC dan inicio a un proceso de repliegue estratégico hacia zonas fronterizas y selváticas del país, llevándose consigo la siembra de coca. Esto explica fundamentalmente los cambios espaciales del conflicto armado colombiano registrados a partir del año 2002 (ver Figura 4), como consecuencia de los efectos de la adopción de una política de confrontación del Estado colombiano hacia los grupos irregulares, no sostenida en toda la geografía nacional. Para el 2002 se incrementa el conflicto en sectores del sur y occidente colombiano, concretamente en los departamentos de Caquetá, Meta, Guaviare y Putumayo, y comienza a insinuarse un incremento del

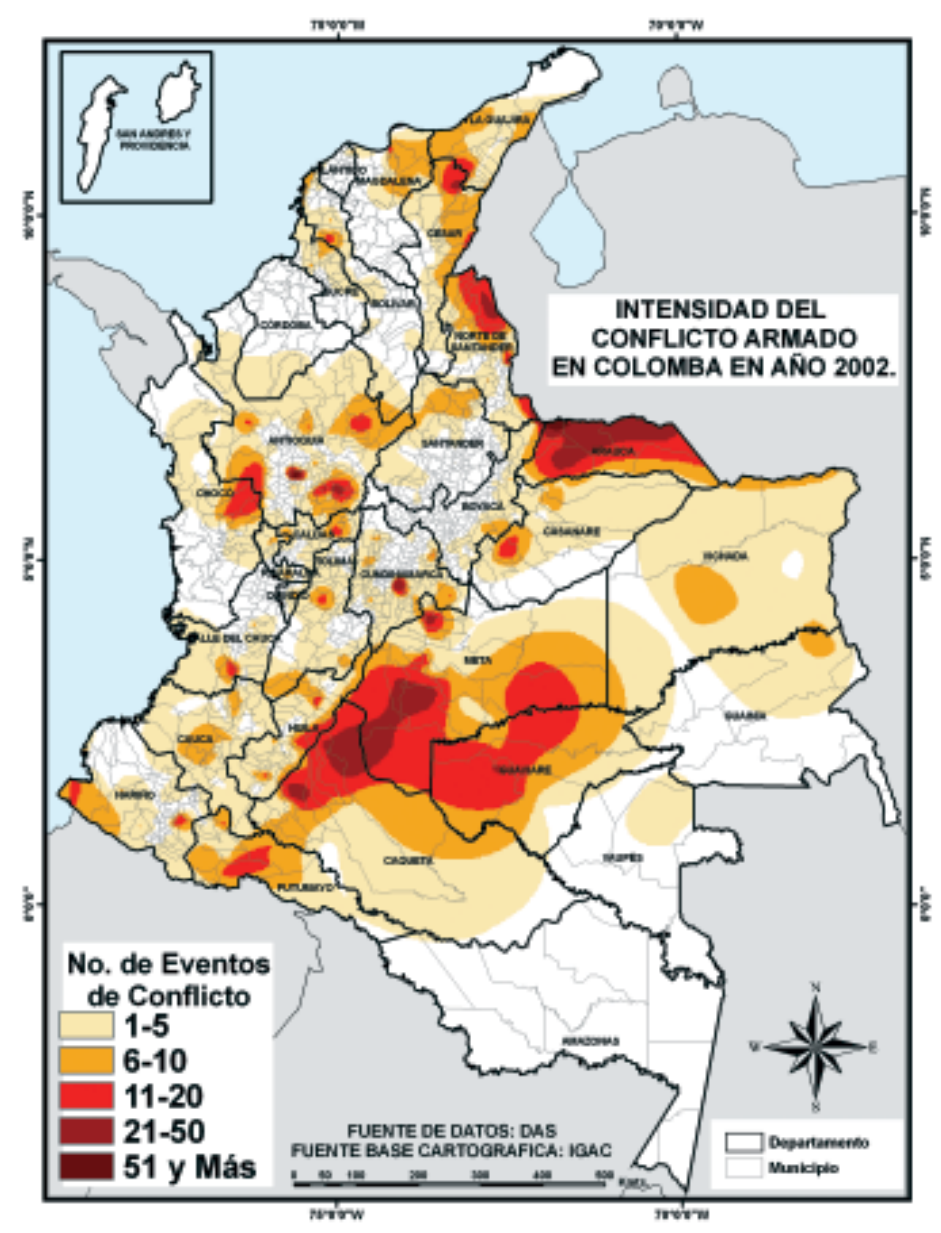

Figura 4. Intensidad del conflicto armado en Colombia, 2002

Fuente: Procesado y elaborado por el autor. 
conflicto armado en el Pacífico colombiano, en los departamentos de Nariño, Cauca, Valle y Chocó.

En la historia reciente del conflicto armado colombiano se destaca la negociación y desmovilización de los grupos de autodefensas, que llevó a cabo el gobierno de Álvaro Uribe Vélez entre los años 2003 y 2006. Se registra la desmovilización de más de 33.000 hombres pertenecientes a las autodefensas en todo el país, según la Oficina del Alto Comisionado para la Paz de la Presidencia de la República de Colombia (2007). Un proceso de paz muy cuestionado a raíz de las evidencias posteriores a este proceso, relacionadas con la reaparición de estructuras armadas en antiguos territorios de control paramilitar, en toda la geografía nacional. Hoy existen serias evidencias de la presencia de grupos armados al servicio del narcotráfico, llamadas bandas criminales, como el caso de las Águilas Negras, los Rastrojos, la Organización Nueva Generación de Paramilitares y los Paisas (OEA, 2007), vinculadas a estructuras ya desmovilizadas, hecho que pone en duda en el ámbito nacional e internacional todo el proceso de desmovilización que adelantó el gobierno de Uribe con estas organizaciones.

La Figura 5 muestra la geografía de la intensidad del conflicto armado colombiano en el año 2009; como se aprecia en este mapa, los niveles de conflicto armado en el conjunto nacional disminuyen, pero se evidencia un incremento en el Pacífico colombiano en comparación con el año 2002. En general, para este año, se identifican cuatro regiones afectadas por el conflicto: Arauca, que mantiene su tendencia histórica; Meta y Caquetá, sobre sectores de la antigua Zona de Distención, y la región del Pacífico colombiano de los departamentos de Nariño, Cauca y Putumayo.

\subsection{Las condiciones geoeconómicas y la estrategia territorial de los actores del conflicto armado colombiano}

Desde finales de la década de los ochenta, Colombia y sus instituciones comienzan a evidenciar grandes transformaciones que, de una u otra manera, han cambiado el curso del conflicto armado interno: primero, la descentralización (política, administrativa y fiscal), y luego, la apertura económica.

A mediados de los años ochenta se inició el proceso de descentralización en Colombia, cuyos objetivos fueron aumentar la provisión de bienes y servicios públicos locales, y el fortalecimiento de la democracia a nivel municipal. Desde sus inicios, se combinó la descentralización política con la descentralización administrativa. Hasta principios de la década de los ochenta, el Estado colombiano era fuertemente centralizado; las decisiones de gasto se tomaban en los organismos del Gobierno Central, mientras el Congreso servía como mediador entre el Gobierno Nacional y las regiones. En este sentido, el propósito inicial de la descentralización se ubicó sobre tres esferas: la política, la administrativa y la fiscal (Sánchez y Chacón, 2002). 


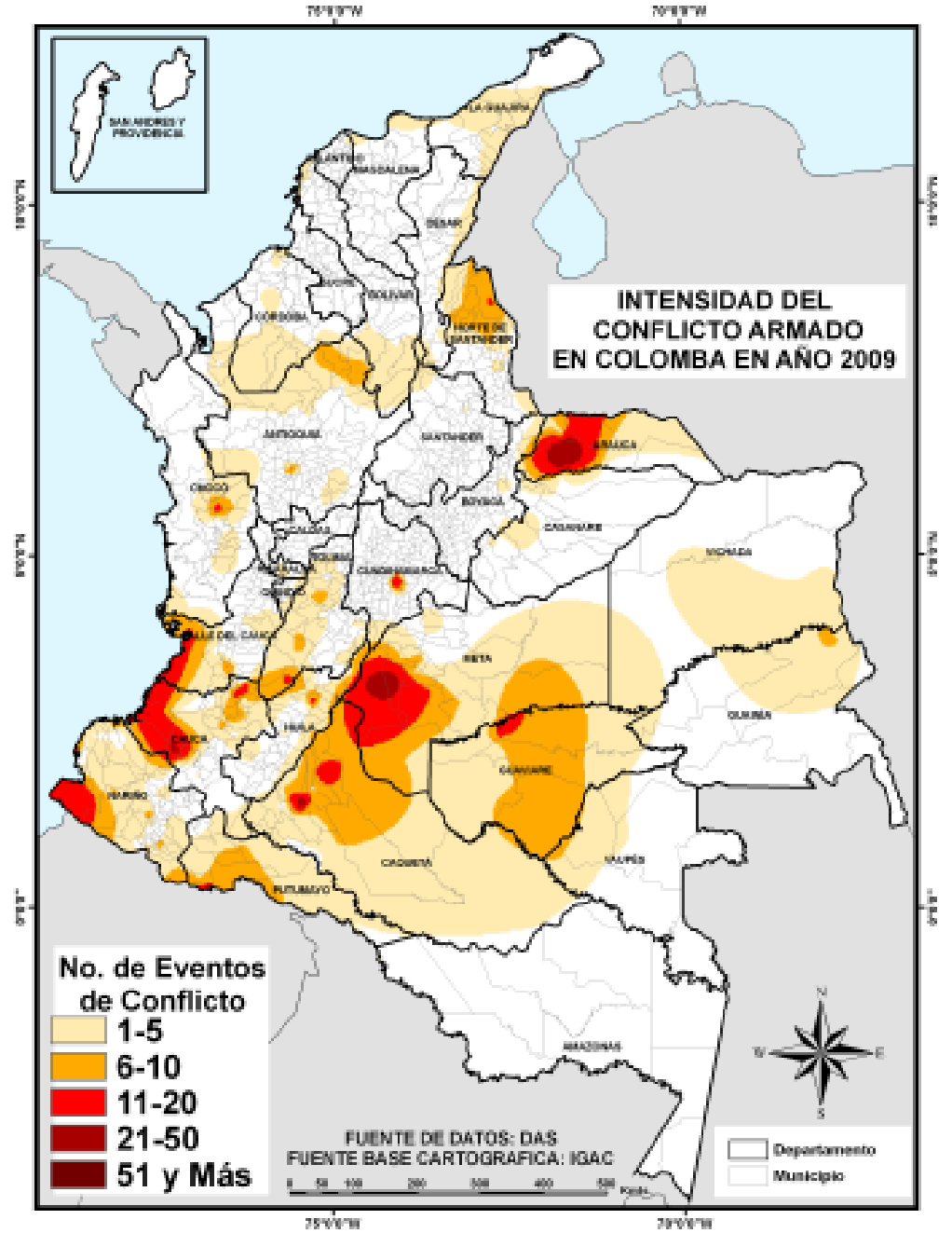

Figura 5. Intensidad del conflicto armado en Colombia, 2009

Fuente: Procesado y elaborado por el autor.

Evidencias empíricas encontradas apuntan a demostrar que el proceso de la descentralización, en todas sus dimensiones, principalmente la fiscal, contribuyó en buena medida a una redefinición de las características del conflicto armado en Colombia, debido a que los actores encontraron en el poder local una oportunidad para acceder a los recursos y posesionarse en estos territorios a través de la coacción armada, para acceder al control y dominio territorial local y regional. En el caso específico de la insurgencia (FARC y ELN), pareciera que vio en la descentralización una puerta para lograr 
sus objetivos originarios de tomarse el poder; como lo expresa Vélez:

La guerrilla colombiana, a partir de la década de los ochenta, amplió sus objetivos expansionistas, al incluir en su mapa de expansión los municipios con niveles de desarrollo superiores a los de los municipios iniciales de colonización. Esto ha implicado en la subversión un plan de crecimiento y un evidente aumento de fuerza, que les posibilitó su presencia en zonas económica, política y militarmente estratégicas, lo cual se ha evidenciado en un incremento de su presencia en municipios con condiciones de vida muy superiores a los municipios rurales iniciales (2000: 15).

Así las cosas, toda la operación territorial está guiada por una operación geopolítica y geoeconómica para fragmentar el país en varias porciones e ir cercando gradualmente su hartland (Moncayo, 2004: 249).

Sánchez y Chacón (2002) concluyen que la mayor actividad y expansión geográfica del conflicto armado colombiano, desde mediados de los ochenta, pero principalmente en los noventa, obedeció al fortalecimiento de sus fuentes de financiación. Para todos los grupos, tanto guerrilleros como paramilitares, el acceso a financiación explica buena parte de la expansión geográfica de sus actividades.

De otro lado, a partir de la consolidación progresiva de la apertura económica en el país, como un efecto de la adopción del Consenso de Washington, el factor económico en los actores irregulares entró a ubicarse en un primer plano, restándole importancia a los factores políticos e ideológicos, especialmente en las organizaciones subversivas. Así las cosas, es a través de la participación de los actores irregulares del conflicto en todos los niveles de la cadena productiva de la coca y heroína, ante la alta demanda internacional, que los grupos irregulares inician una nueva etapa del conflicto por la lucha y consolidación de territorios productores de cultivos ilícitos y de rutas de comercialización. A partir de entonces, el narcotráfico se configura en el nuevo combustible por excelencia del conflicto armado colombiano. La apabullante presencia del narcotráfico no haría más que desvertebrar y desprestigiar más un liderazgo de por sí extremadamente frágil y desprestigiado, y, a la par, reventaría el frágil Estado colombiano (Palacios, 1996).

La apertura económica y la reestructuración industrial conllevan, como toda reforma, cambios en los roles de algunos agentes, pérdida de poderes adquiridos, recomposición de poderes y nuevas alianzas (Misas, 1991), y esto aplica también a las estructuras mafiosas y a los actores del conflicto armado colombiano. Para comprender mejor el impacto en el conflicto armado en colombiano de la apertura económica y de la consolidación de una economía globalizada, Pécaut (2008), al referirse a los recursos financieros de las FARC y de todos los actores armados irregulares, menciona que estos actúan en la actualidad bajo una lógica económica, como lo demuestran los trabajos de economistas del Banco Mundial como 


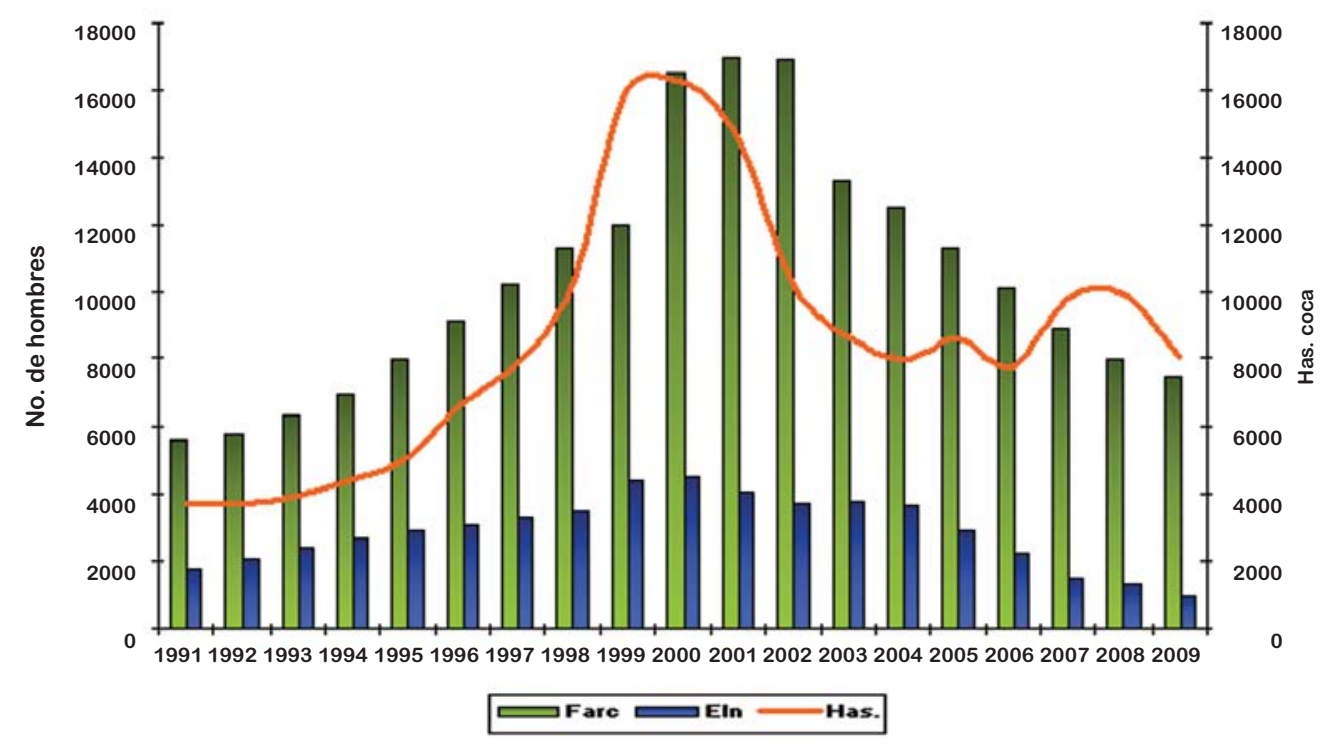

Figura 6. Evolución en el número de combatientes de las FARC y el ELN, y en las hectáreas de coca en Colombia, 1991 a 2009

Fuente de datos hectáreas de coca: Policía Nacional, ONUDC y Departamento de Estado de los EE.UU. (19911999); del 2000 al 2009 corresponde a la información de SIMCI. Número de hombres: Ministerio de Defensa, Observatorio del Programa Presidencial de DD.HH y DIH. Procesado y elaborado por el autor.

Paul Collier (2002). Collier expone que la mayoría de los conflictos actuales locales no responden a reivindicaciones, sino a oportuni-dades de depredación. Esas particula-ridades son especialmente poderosas en el caso de economías que dependen principalmente de la exportación de materias primas, y en especial de materias primas que pueden ser objeto de contrabando, que aplica para el caso colombiano. Por lo tanto, los actores del conflicto, aun manteniendo el discurso de reivindicaciones sociales que les dieron origen, tienden a actuar, sobre todo, en función de sus objetivos económicos (ver figura 6).
Las figuras 7 y 8 muestran las acciones armadas de los grupos irregulares y las áreas sembradas de coca en los años 2002 y 2009. Al observar estos mapas se identifica un patrón espacial muy claro de correlación entre las áreas de siembra de coca y el accionar armado de los grupos irregulares, evidenciando una alta relación entre incremento del conflicto armado y siembra de coca. Al comparar los dos mapas, es irrefutable que la dinámica espacial del accionar de los grupos irregulares y, por ello, del conflicto armado colombiano está determinada en gran medida por la dinámica y difusión espacial del cultivo de coca. 


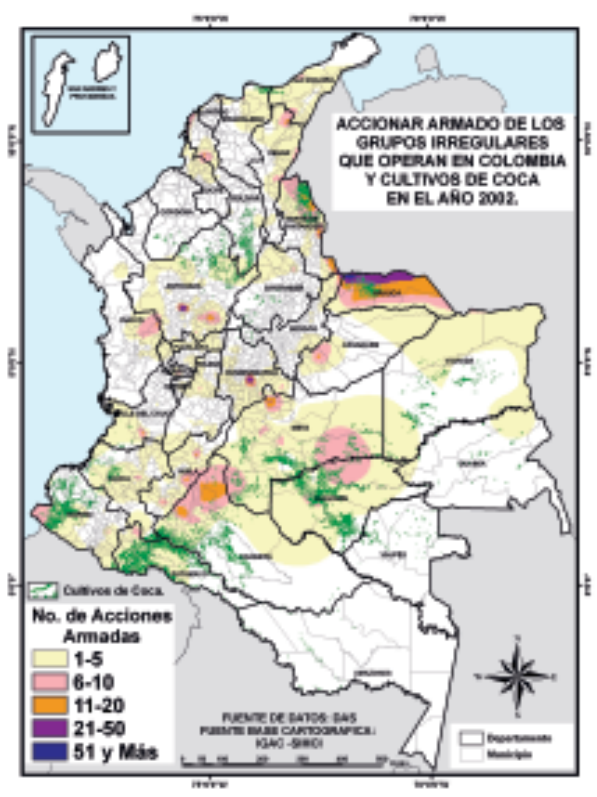

Figura 7. Accionar armado de los grupos irregulares y cultivos de coca en Colombia, 2002

Fuente: Procesado y elaborado por el autor.

La estrategia territorial de los actores del conflicto armado colombiano está determinada, fundamentalmente, por las condiciones geoeconómicas de la guerra, como se ha demostrado y se mostrará a continuación. La Figura 9 muestra los territorios de control armado de las guerrillas (en azul) y de las Fuerzas del Estado (en verde), y los territorios en disputa armada y de alta intensidad de conflicto entre los actores armados por su control (en rojo), así como los cultivos de coca en el año 2003. Se considera este año porque a partir de él se evidencian los principales cambios en la dinámica espacial del conflicto armado reciente en Colombia, consistentes en el desplazamiento del conflicto armado de unas regiones hacia otras. Analizando

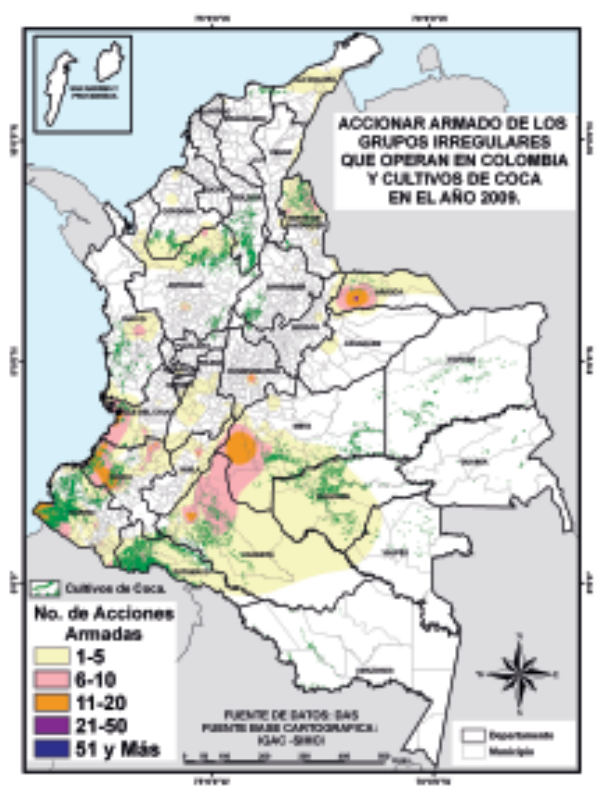

Figura 8. Accionar armado de los grupos irregulares y cultivos de coca en Colombia, 2009

Fuente: Procesado y elaborado por el autor.

este mapa, se evidencia que tanto la disputa como el control armado de los actores del conflicto son un fenómeno focalizado y no disperso por toda la geografía colombiana. Esto sugiere un interés específico de los actores armados sobre territorios estratégicos, y está relacionado con dos factores, fundamentalmente: los valores geoeconómico y geoestratégico de los territorios.

En cuanto al valor geoeconómico, obsérvese en la Figura 9 cómo las áreas de mayor disputa armada (color rojo) coinciden con los escenarios de mayor cultivo de coca, con excepción del Bajo Cauca antioqueño y el sur de Bolívar, que corresponden a territorios ya 
consolidados por los grupos paramilitares, pero que a su vez son corredores del narcotráfico. En cuanto al valor geoestratégico, los territorios en color azul y verde, que muestran control armado de las guerrillas y de las fuerzas del Estado, respectivamente, sucede en general sobre áreas con poca concentración de cultivos de coca y sobre territorios de alta montaña y medios de transporte (fluvial y terrestre), que configuran así los corredores estratégicos de movilidad para los actores armados y que permite la comunicación entre las regiones del país. Esto sugiere que el conflicto armado colombiano se explica en buena medida por las pretensiones de poder y de control de los actores armados sobre los territorios de coca y potencial económico, y los corredores estratégicos que ofrecen ventajas y garantizan la conducción de la guerra en Colombia (Pécaut, 2004).

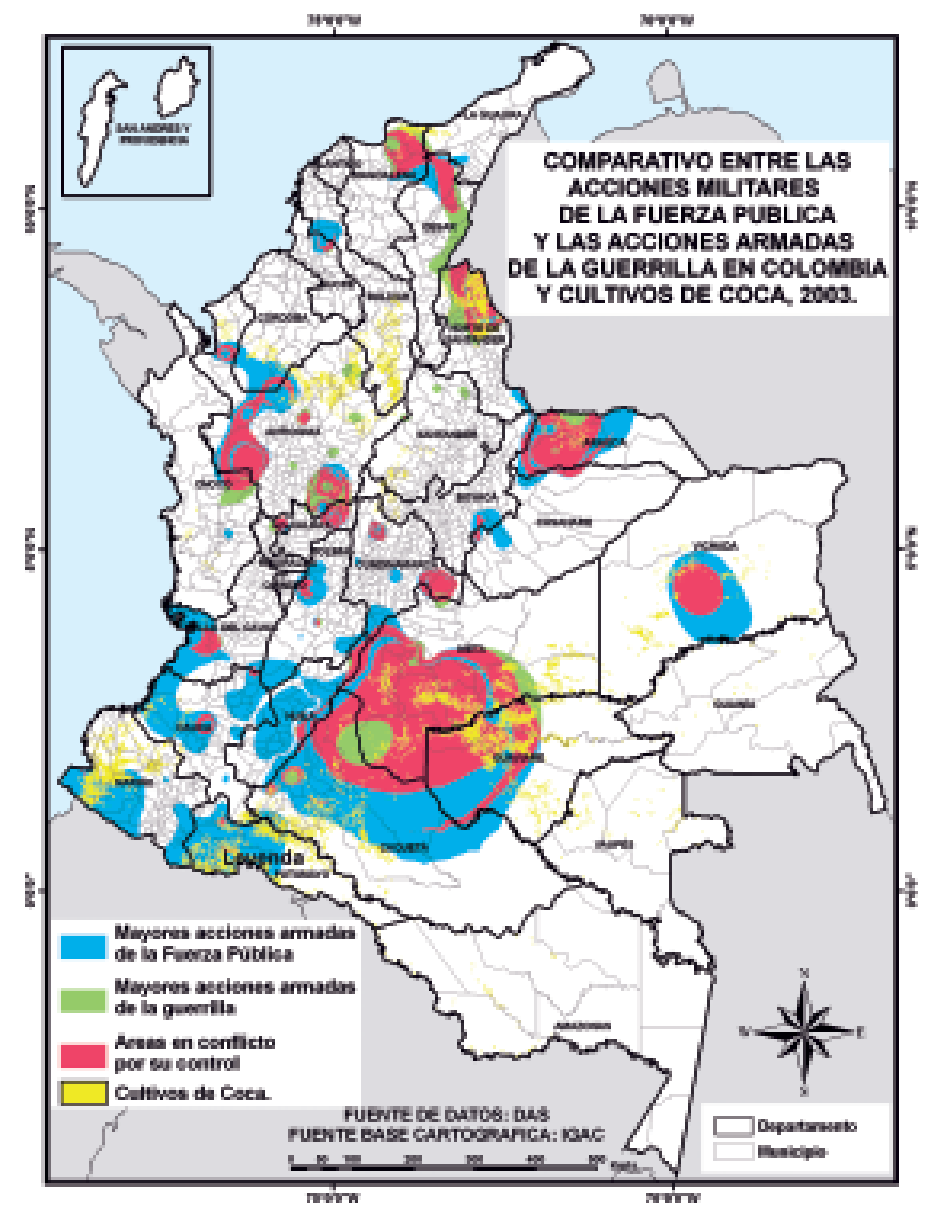

Figura 9. Comparativo entre las acciones militares de la Fuerza Pública y las de la guerrilla, y cultivos de coca en el 2003

Fuente: Procesado y elaborado por el autor. 


\subsection{La estrategia territorial de los actores del conflicto armado en el suroccidente colombiano, como estudio de caso}

Se ha identificado que la estrategia territorial de los actores del conflicto armado colombiano se presenta en tres niveles: el nacional, el regional y el local; por ello, se caracteriza a continuación la estrategia territorial de los actores del conflicto armado de una de las regiones de Colombia: el Suroccidente colombiano, integrada por los departamentos de Nariño y Putumayo.

La región del Suroccidente colombiano tiene un área de $58.916 \mathrm{~km}^{2}$, que representan el 5,16\% del territorio nacional, y cuenta con $1.133 \mathrm{~km}$ de frontera: 313 marítimos (28\%) y 820 terrestres $(72 \%)$; de la frontera terrestre, el $79 \%(649 \mathrm{~km})$ es con la República del Ecuador y el $21 \%(170 \mathrm{~km})$ con la República del Perú. Esta región presenta tres grandes zonas geográficas: Llanura del Pacífico, zona Andina y Amazónica, las cuales permiten caracterizarla por múltiples paisajes y ecosistemas estratégicos, que han sido parte de las pretensiones de control de los actores del conflicto armado.

En su conjunto, el Suroccidente colombiano ha sido tradicionalmente marginal y periférico de Colombia, lo cual ha facilitado que se constituya en un enclave de los actores armados irregulares. Marginal, puesto que además de contener economías de enclave y el manejo de negocios ilícitos supremamente rentables, basados en los cultivo de coca y amapola, es una de las regiones más pobres del país, y periférica, porque es la frontera con los vecinos países de Ecuador y Perú, en contacto con la selva amazónica y con la costa Pacífica (Jiménez R., 2009).

A lo largo del conflicto armado colombiano, y especialmente a partir de la década de los noventa, el Suroccidente colombiano se ha constituido en territorio geostratégico para sus actores, desde el punto de vista geopolítico y geoeconómico, especialmente para las FARC, el ELN, los narcotraficantes y los grupos paramilitares; controlar este territorio entrega una ventaja que asegura la conducción de la guerra (Pécaut, 2004).

Al analizar la distribución espacial de los eventos del conflicto (1990-2009), asociados a escenarios claramente identificados en la región del Suroccidente colombiano, como carreteras, centros urbanos, infraestructura energética-petrolera, ríos, áreas de montaña y zonas de frontera, ha sido posible identificar cuatro corredores estratégicos del conflicto armado en la región: los corredores de alta montaña, los corredores de carreteras, los corredores fluviales y el corredor fronterizo. Estos corredores estratégicos se caracterizan por permitir a los actores del conflicto en la región la movilidad de tropas, comida, armas, drogas y otros elementos indispensables para la continuidad de la guerra. Mantener el control de estos corredores o de alguno de sus tramos representa ventajas significativas en la conducción de la guerra, y garantiza la continuidad en la condición de actor hegemónico para un actor del conflicto armado de la región. 
Las figuras 10, 11, 12 y 13 muestran los corredores estratégicos identificados; estos se comportan, en el espacio del Suroccidente colombiano, como una malla o red en donde los actores del conflicto interactúan y territorializan algunos de sus tramos, lo que permite comprender el valor estratégico del espacio como un elemento determinante para explicar el conflicto armado de la región. Identificar estos corredores representa tan solo un elemento más para explicar la dinámica de las territorialidades en el contexto del conflicto armado en esta región, y se configura en el primer nivel de territorialidad identificado.

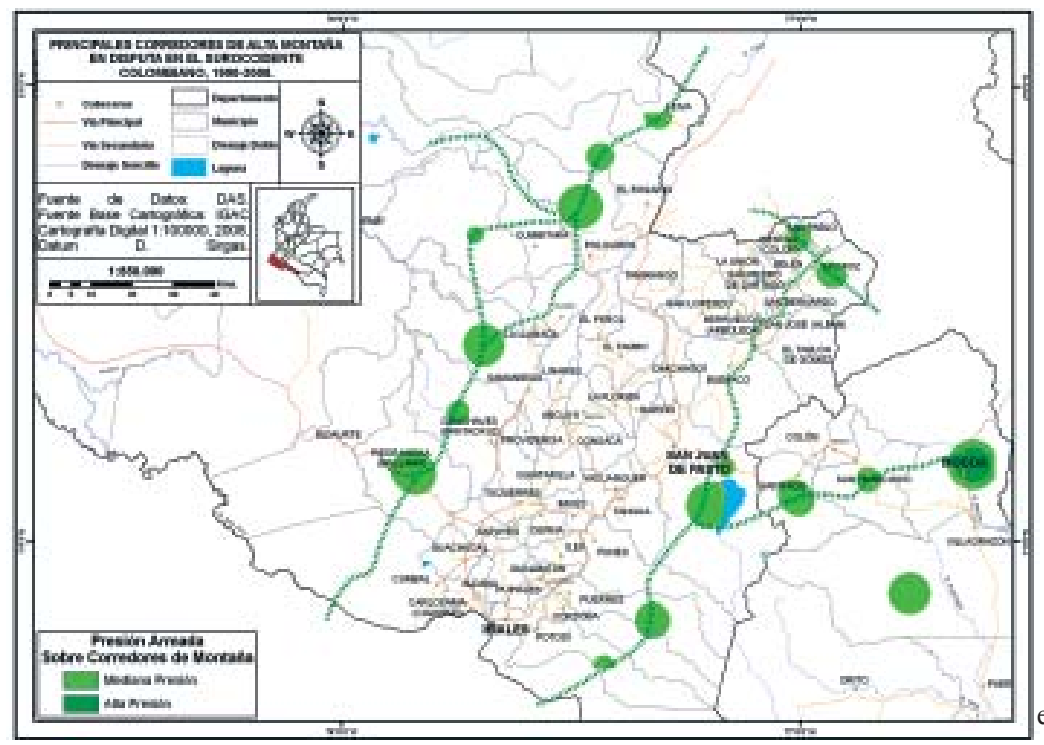

Figura 10.

Corredores estratégicos de alta montaña

Fuente: Procesado y elaborado por el autor.

Figura 11. Corredores estratégicos de carreteras

Fuente: Procesado y elaborado por el autor.

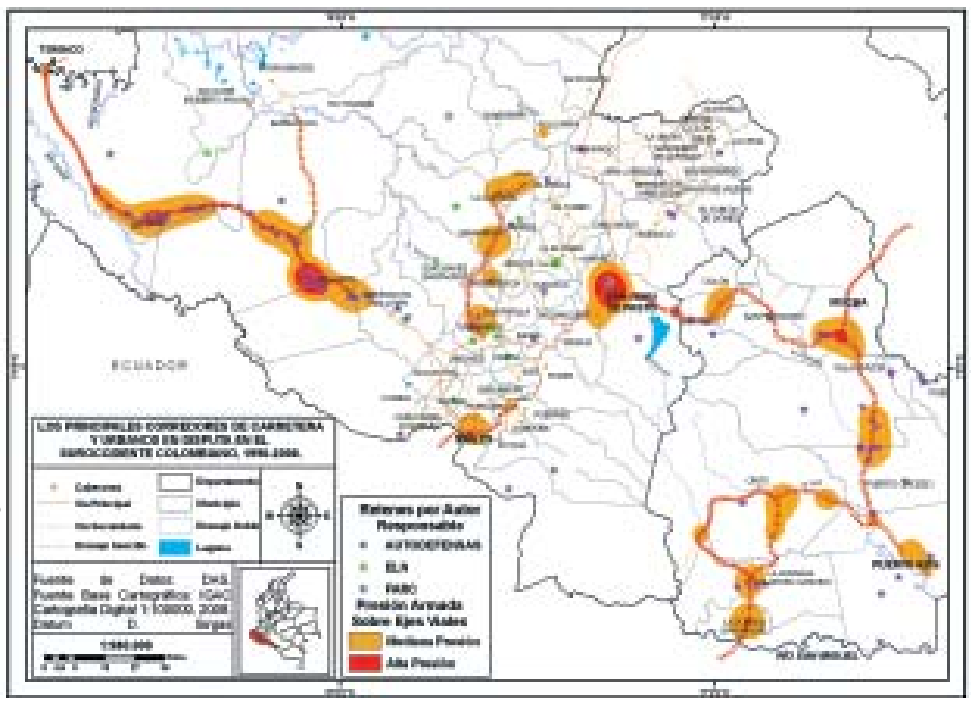

\begin{tabular}{l|l} 
Perspect. geogr. Vol. 15. Año 2010, pp. 9-36 & 25
\end{tabular} 


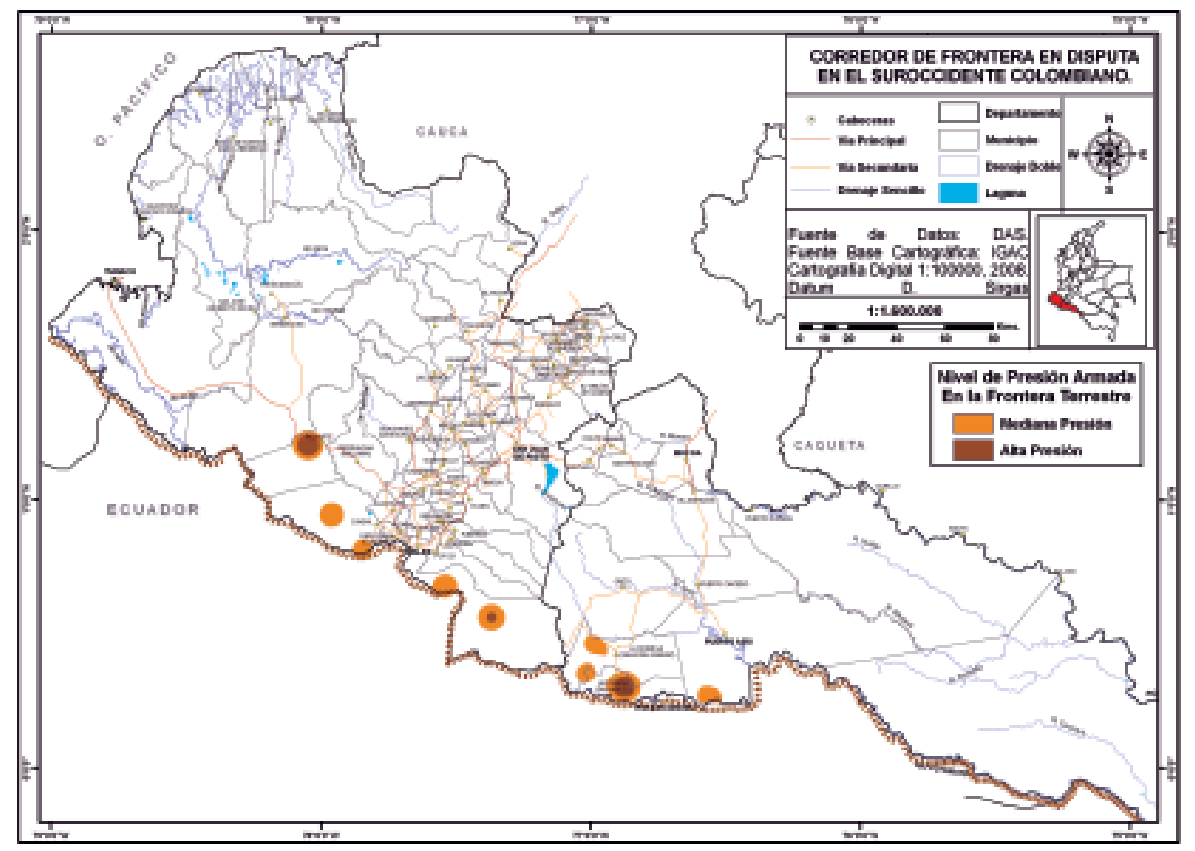

Figura 12. Corredor estratégico de frontera

Fuente: Procesado y elaborado por el autor.

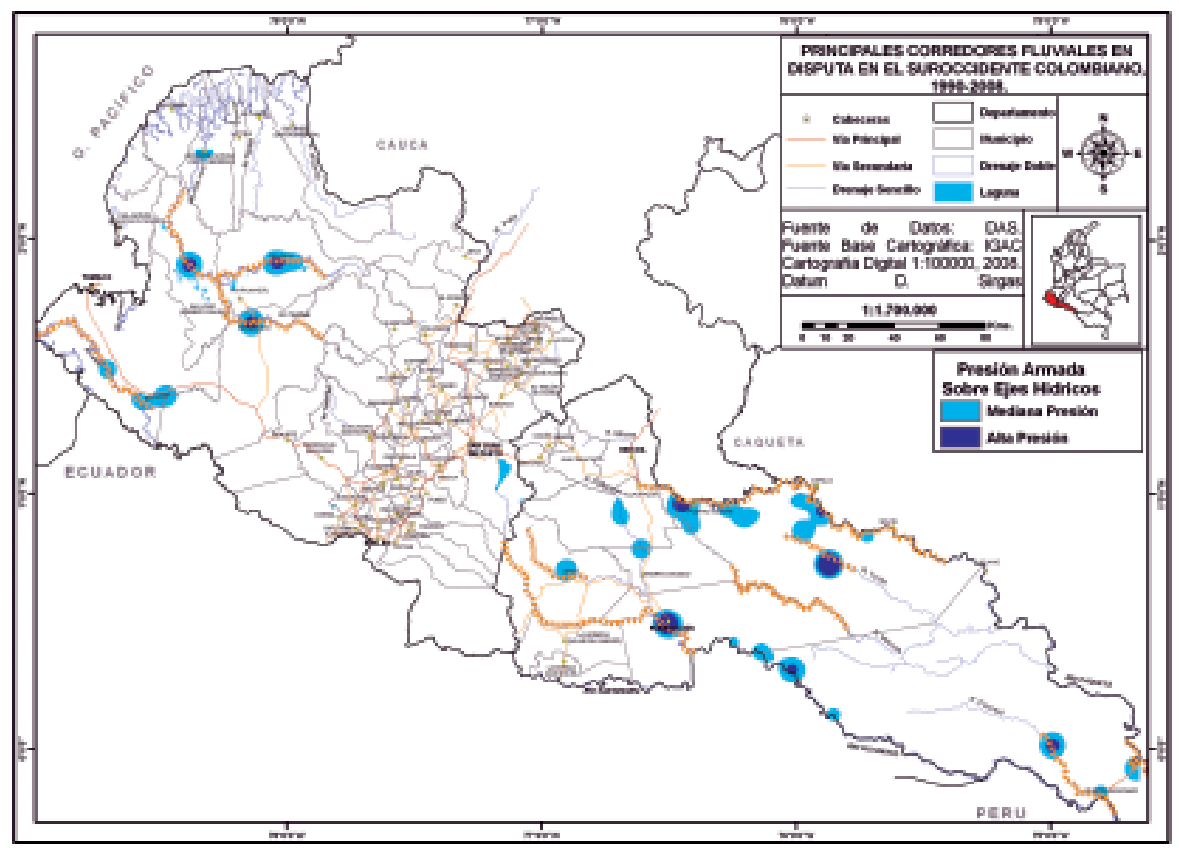

Figura 13. Corredores estratégicos fluviales

Fuente: Procesado y elaborado por el autor.

26 Luis Gabriel Salas Salazar 
Los corredores estratégicos identificados constituyen, en la lógica de los actores del conflicto armado, la principal fuente de movilidad por la región y fuera de ella, ya que configuran una compleja red o malla que se distribuye por toda la geografía de la región y permite la comunicación hacia el interior del país, la Amazonia colombiana, Ecuador y Perú y hacia el océano Pacífico. No obstante, se ha identificado que en aquellos espacios en donde dos o más corredores estratégicos confluyen, se configuran siete territorios estratégicos del conflicto armado en la región (ver Tabla 1 y Figuras 14, 15 y 16), concordando así el segundo momento en la estrategia de la territorialidad de los actores armados del conflicto en la región (ver Figura 17).

Tabla 1. Territorios estratégicos en disputa de apropiación por los actores del conflicto armados en la región del Suroccidente colombiano

\begin{tabular}{|c|c|c|c|c|c|c|c|}
\hline \multirow{2}{*}{\begin{tabular}{|c|} 
REGIONES \\
FSIOGRÁFCAS \\
TERRITORIOS \\
ESTRATÉGICOS
\end{tabular}} & \multicolumn{2}{|c|}{ PACÍFICA } & \multicolumn{3}{|c|}{ ANDINA } & \multicolumn{2}{|c|}{ AMAZÓNICA } \\
\hline & $\mathbf{P 1}$ & P2 & A1 & A2 & A3 & M1 & M2 \\
\hline \multirow{8}{*}{ MUNICIPIOS } & TUMACO & BARBACOAS & POUCARPA & IPIALES & PASTO & SANMGUE & PUERTOCAICEDO \\
\hline & RICAURTE & MAGÜ'PAYÁN & CUMBITARA & PUPIALES & BUESACO & LAHORMGA & VШAGARZÓN \\
\hline & & ROBERTOPAYÁN & SOTOMAYOR & ALDANA & SANTIAGO & ORTO & \\
\hline & & & LAШANADA & CUMBAL & COLÓN & PUERTOASÍS & \\
\hline & & & SAMANEGO & CARLOSAMA & SANFRANCISCO & & \\
\hline & & & UNARES & & SIBUNDOY & & \\
\hline & & & GUACHAVEZ & & & & \\
\hline & & & PIEDRANCHA & & & & \\
\hline
\end{tabular}

Fuente: Elaborado por el autor.

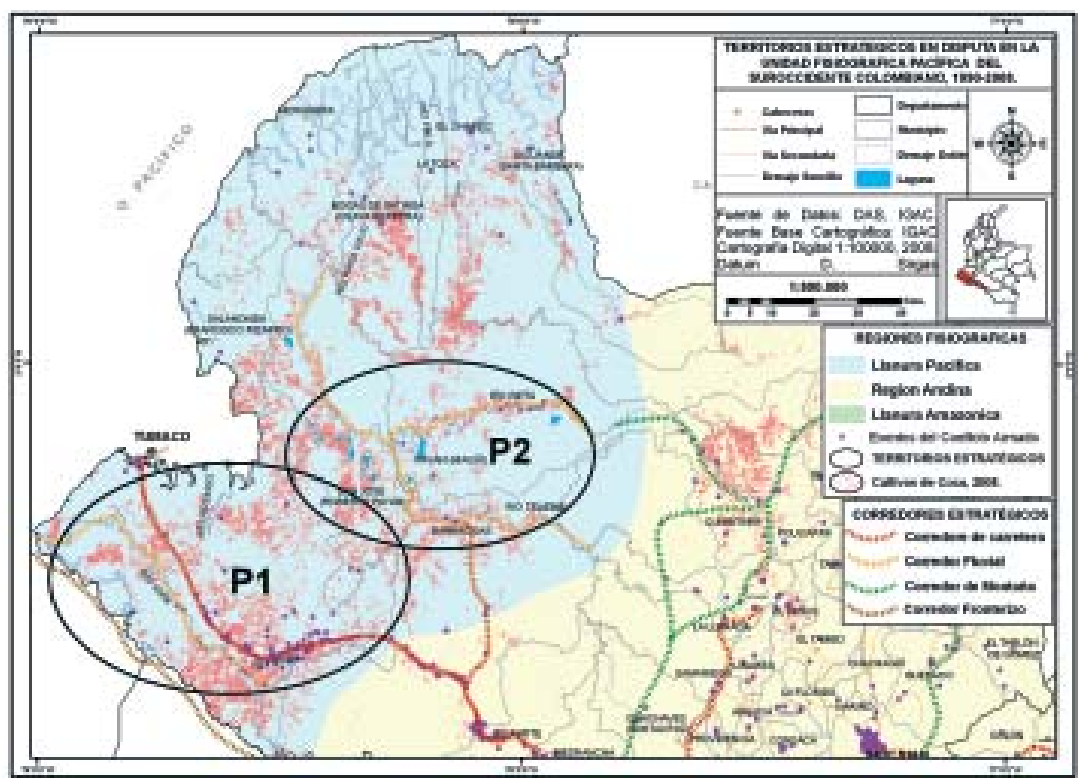

Figura 14. Territorios estratégicos en disputa en la unidad fisiográfica Pacífica del Suroccidente Colombiano, 2009

Fuente: Procesado y elaborado por el autor. 


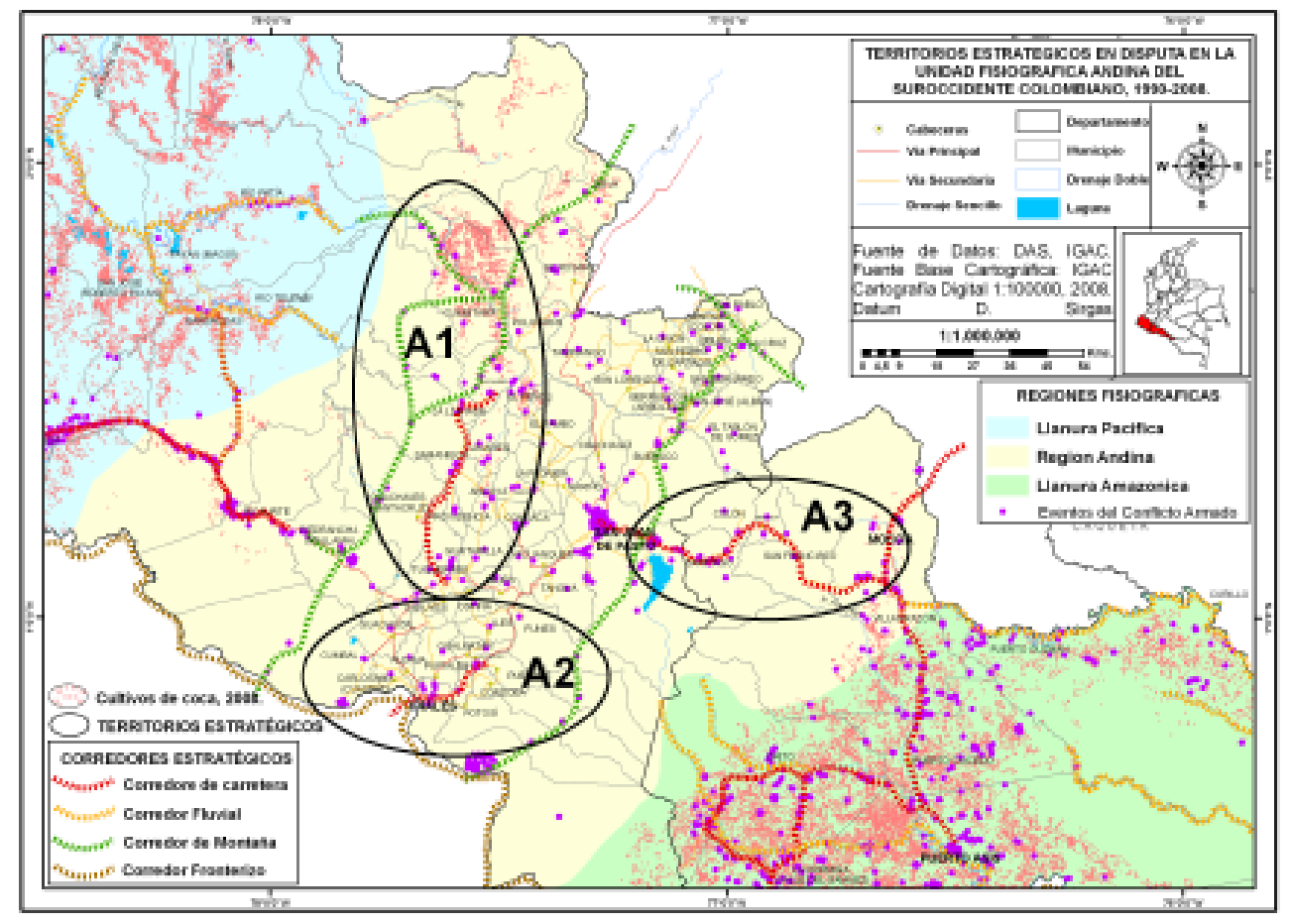

Figura 15. Territorios estratégicos en disputa en la unidad fisiográfica Andina del Suroccidente Colombiano, 2009

Fuente: Procesado y elaborado por el autor.

Se entiende por territorios estratégicos aquellos espacios geográficos de la región configurados a partir de la confluencia de dos o más corredores estratégicos identificados en ella, y que los actores armados pretenden controlar por su importancia geoeconómica, dada la presencia de cultivos de coca y recursos naturales, o geoestratégica, dada por la facilidad de movilidad en la región y hacia afuera. 


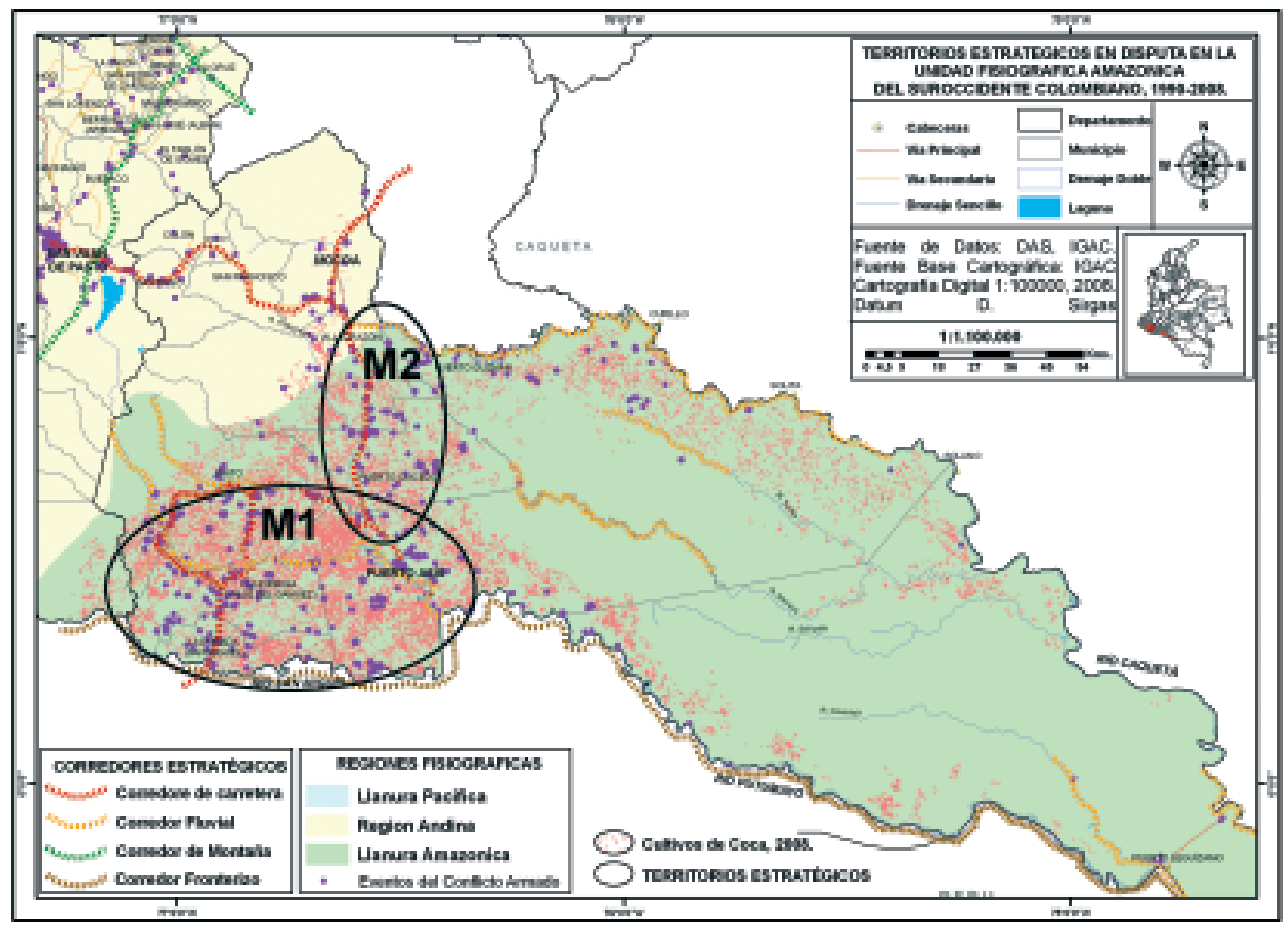

Figura 16. Territorios estratégicos en disputa en la unidad fisiográfica Amazónica del Suroccidente Colombiano, 2009

Fuente: Procesado y elaborado por el autor.

Ningún actor armado ha logrado la territorialidad total de estos territorios; se identifica una presencia y control de estos sobre algunos tramos de los territorios estratégicos, evidenciando un tercer momento de territorialidad (ver Figura 17). En todos los territorios estratégicos, sin excepción, hacen presencia todos los actores armados del conflicto, lo cual explica los altos índices de violencia y de conflicto armado registrados en ellos. En estos territorios estratégicos, además de las territorialidades evidentes, se perciben coexistencias de territorialidades y disputas de territorialidades entre los actores del conflicto armado de la región. 


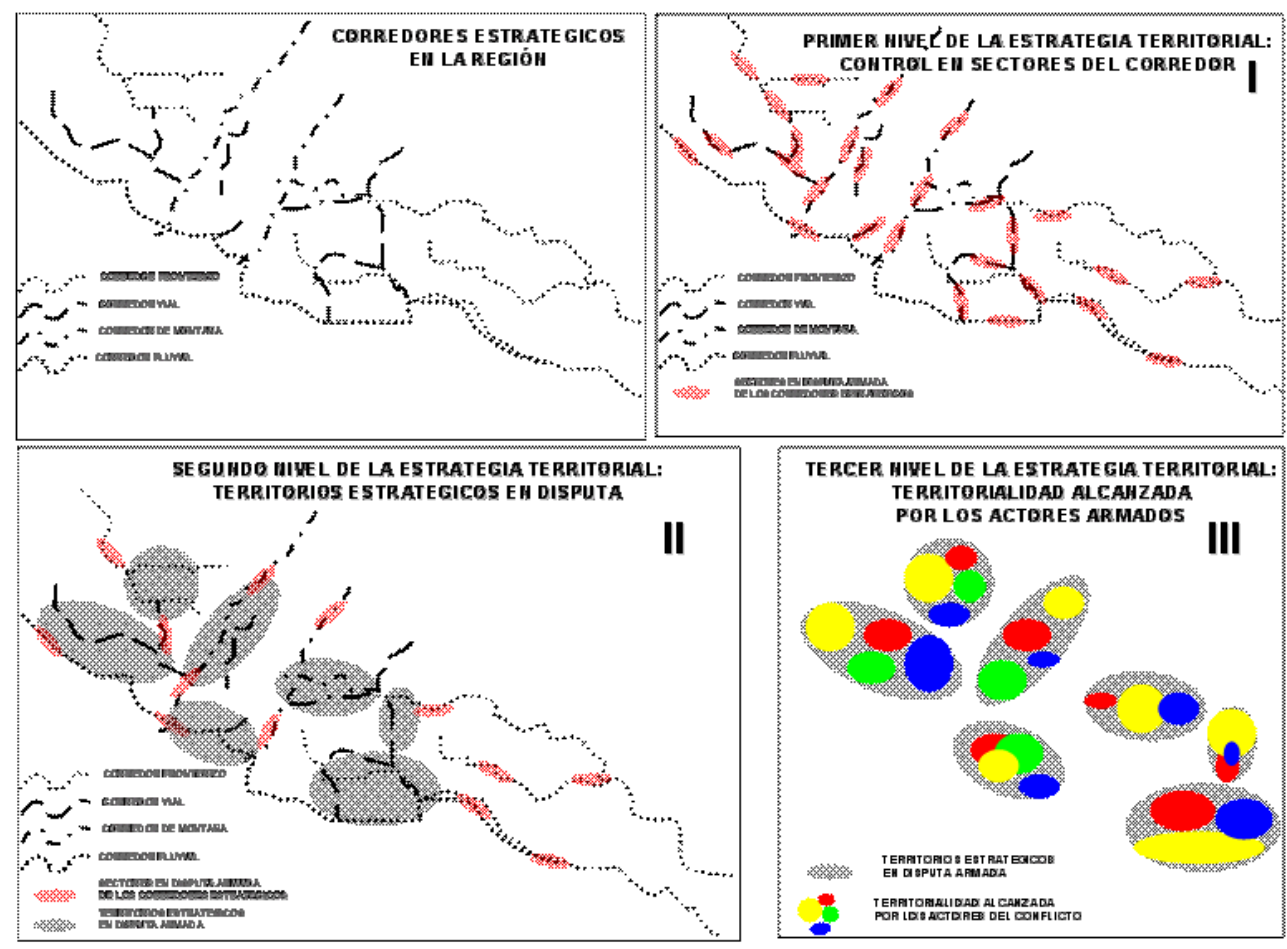

ESTRA TEGIA TERRTTORIAL DE LOS ACTORES DEL CONFLICTO ARMADO EN EL SUROCCIDENTE COLOMBIANO.

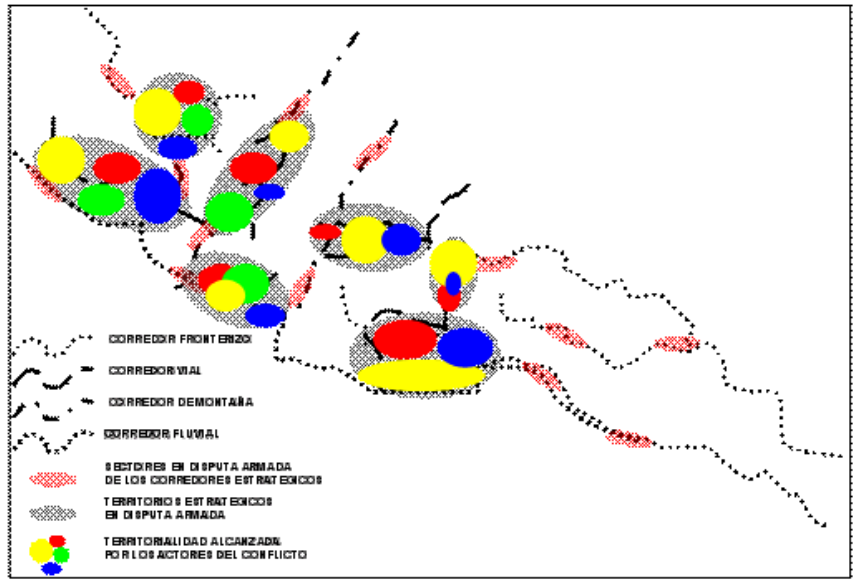

Figura 17. Momentos en la estrategia territorial de los actores armados del conflicto en la región del Suroccidente colombiano

Fuente: Procesado y elaborado por el autor. 
Durante el periodo 1990-2008, estos territorios estratégicos no han mantenido la misma prioridad de apropiación y disputa por su control para los actores armados; según la propia dinámica territorial del conflicto armado, algunos registran mayor intensidad armada que otros; la Figura 18 lo demuestra.

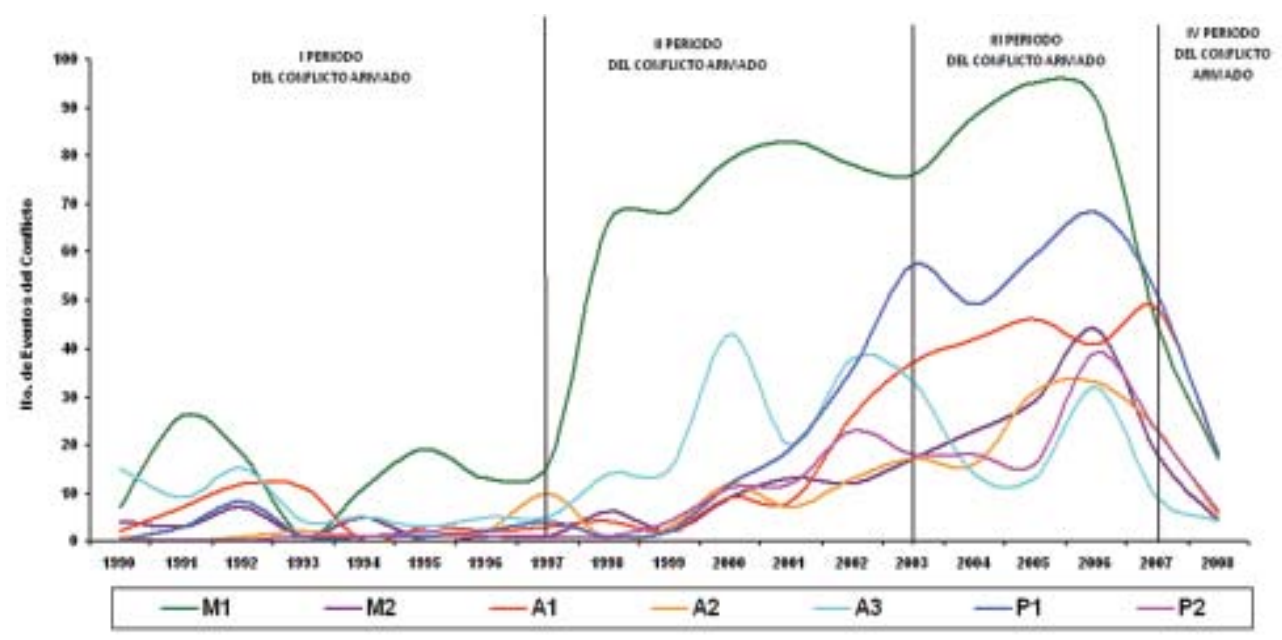

Figura 18. Dinámica de la intensidad del conflicto armado en los territorio estratégicos definidos en el Suroccidente colombiano, 1990-2008

Fuente de datos: Das; procesado y elaborado por el autor.

Para comprender mejor las formas de territorialidad ejercidas por los actores del conflicto armado que operan en la región en los corredores y territorios estratégicos, y sobre la búsqueda del poder local, se presenta la Tabla 2, en la que además de identificar las principales formas de territorialidad ejercidas en la región por cada actor armado que en ella opera, se pondera el nivel de incidencia en cada una de ellas según el actuar de cada actor del conflicto armado. En la región se identifican tres maneras fundamentales de territorialidad: a través de acciones de índole militar, de violación de derechos humanos y de búsqueda de poder local. Se identifican diferencias notables en el accionar armado entre los grupos armados de extrema derecha (paramilitares) y los grupos armados de extrema izquierda (guerrillas), como también entre estos últimos; se puede identificar que la guerrilla de las FARC recurre a acciones armadas, principalmente, como el mecanismo más eficiente de territorialidad. 
Tabla 2. Tipificación de las prácticas de ejercicio de las territorialidades de los actores armados que hacen presencia en el Suroccidente colombiano

\begin{tabular}{|c|c|c|c|c|c|c|}
\hline \multicolumn{2}{|c|}{ ACTORES DEL CONFLICTO } & \multirow[b]{2}{*}{ FARC } & \multirow[b]{2}{*}{ ELN } & \multicolumn{2}{|c|}{ PARAMILILTARES } & \multirow{2}{*}{$\begin{array}{l}\text { FUERZA } \\
\text { PÚBLICA }\end{array}$} \\
\hline TIPOACCIÓN & FORMAS EJERCIDAS & & & AUTODEFENSAS & G. EMERGENTES & \\
\hline \multirow{8}{*}{ Militar } & Combates & $\mathrm{N}$ & $\mathrm{N}$ & $\mathrm{N}$ & $\mathrm{N}$ & A \\
\hline & Hostigamientos & $A$ & $B$ & $\mathrm{~N}$ & $\mathrm{~N}$ & $\mathrm{~N}$ \\
\hline & Ataques a poblaciones & A & $B$ & $\mathrm{~N}$ & $\mathrm{~N}$ & $\mathrm{~N}$ \\
\hline & Emboscadas & $\mathrm{M}$ & $B$ & $B$ & $B$ & $\mathrm{~N}$ \\
\hline & Enfrentamientos & $\mathrm{M}$ & $\mathrm{M}$ & $\mathrm{M}$ & $M$ & $\mathrm{~N}$ \\
\hline & Retén & A & $\mathrm{M}$ & $\mathrm{M}$ & M & A \\
\hline & Actos terroristas & A & $B$ & $\mathrm{~B}$ & $B$ & $\mathrm{~N}$ \\
\hline & Registro y control & $\mathrm{M}$ & $B$ & M & $\mathrm{M}$ & A \\
\hline \multirow{8}{*}{$\begin{array}{l}\text { Violación } \\
\text { humanitaria }\end{array}$} & Asesinatos & $\mathrm{M}$ & $\mathrm{B}$ & A & A & $B$ \\
\hline & Masacres & $\mathrm{M}$ & $B$ & A & A & $B$ \\
\hline & Secuestros & $\mathrm{M}$ & $B$ & $\mathrm{M}$ & $\mathrm{M}$ & $\mathrm{N}$ \\
\hline & Desapariciones & $\bar{M}$ & $\mathrm{~B}$ & $\mathrm{~A}$ & $A$ & $\mathrm{~N}$ \\
\hline & Amenazas & A & $\mathrm{A}$ & $\mathrm{A}$ & $\mathrm{A}$ & $\mathrm{N}$ \\
\hline & Desplazamientos & A & $\mathrm{B}$ & A & A & A \\
\hline & Uso de minas antipersonal & $\mathrm{A}$ & $\mathrm{A}$ & $B$ & $B$ & $\mathrm{~N}$ \\
\hline & Despojo de tierra & $B$ & $B$ & A & A & $\mathrm{N}$ \\
\hline \multirow{7}{*}{$\begin{array}{l}\text { Control del } \\
\text { poder local }\end{array}$} & Veto territorial & $\mathrm{M}$ & $B$ & $\mathrm{~A}$ & $\mathrm{~A}$ & $\mathrm{~N}$ \\
\hline & Veto electoral & A & A & A & A & $\mathrm{N}$ \\
\hline & Favoreciemiento electoral & $\bar{M}$ & $\mathrm{~B}$ & $\mathrm{~A}$ & $\mathrm{~A}$ & $\mathrm{~N}$ \\
\hline & Amenazas funcionarios públicos & M & $B$ & A & A & $\mathrm{N}$ \\
\hline & Llamado a rendir cuentas & $\mathrm{M}$ & $\mathrm{M}$ & $\mathrm{M}$ & $\mathrm{M}$ & $\mathrm{N}$ \\
\hline & Nombramiento recomendado & $\mathrm{M}$ & $\mathrm{M}$ & $A$ & $A$ & $\mathrm{~N}$ \\
\hline & Presión en ejecución de obras & $\mathrm{M}$ & $\mathrm{M}$ & $\mathrm{A}$ & $A$ & $\mathrm{~N}$ \\
\hline
\end{tabular}

Nivel de acción de prácticas de territorialidad

\begin{tabular}{|c|c|}
\hline Alto & A \\
\hline Medio & $\mathrm{M}$ \\
\hline Bajo & $\mathrm{B}$ \\
\hline Nulo & $\mathrm{N}$ \\
\hline
\end{tabular}

\section{Conclusiones}

- La dinámica de las territorialidades de los corredores y territorios estratégicos del conflicto armado colombiano se ha desplegado a través de tres niveles: el nacional, el regional y el subregionallocal. Para cada uno de ellos existe una dinámica territorial en donde los actores armados del conflicto han desplegado sus operaciones militares, económicas y políticas, configurando una condición multiescalar de las territorialidades. Cuando las

Fuente: Elaborado por el autor a partir de la información de bases de datos y su propio análisis.

vocaciones de control y de poder de los actores del conflicto armado se debilitan en el nivel nacional, la disputa sobre los corredores y territorios estratégicos se hace más interna, en los niveles regionales y subregional-locales.

- La territorialidad ejercida por los actores del conflicto armado colombiano se manifiesta a través de una estrategia que busca el control territorial de pequeños espacios sobre los corredores y territorios estratégicos 
en tres momentos (ver Figura 17), y en cada uno de ellos ejercer un control absoluto sobre puntos específicos del espacio geográfico, que no representan espacios grandes, para luego ponderarlo hacia territorios más extensos.

- En cada momento del conflicto armado nacional, regional y local ocurren nuevas y variadas formas de ejercicio de las territorialidades de los actores del conflicto. Entre algunos de estos actores se da la coexistencia de territorialidades, en disputa con la territorialidad de otros actores.

- La dinámica de las territorialidades, evidente en Colombia y en la región del Suroccidente colombiano desde 1990 hasta 2009, registra un fenómeno de difusión muy similar a lo ocurrido con los cultivos de coca. Así, el componente geoeconómico del conflicto armado colombiano, fundamentado en los cultivos ilícitos, especialmente en la coca, se constituye en la principal prioridad geopolítica de los grupos armados irregulares y explica en gran medida las difusiones espaciales de la violencia y el conflicto armado nacional, regional y local.

- En cuanto a las prácticas de los actores del conflicto armado por controlar e incidir sobre los espacios en disputa de territorialidad (corredores y territorios estratégicos), se identifica que no han sido las mismas para todos los actores armados, ni tampoco los actores armados ejercen las mismas prácticas de control en todos los espacios objeto de su territorialidad.

- Ha sido posible diferenciar un patrón que muestra las acciones ofensivas y de repliegue entre los dos grandes actores armados identificados (subversión vs. Fuerza Públicaparamilitares). Se ha identificado que en la disputa por el control territorial de los corredores y territorios estratégicos del conflicto armado nacional, regional y local, las acciones armadas de las Fuerzas del Estado aumentan (momento ofensivo) inmediatamente bajan las acciones de las guerrillas en un repliegue estratégico; se configura así un ciclo vicioso de la guerra, en donde las partes del conflicto no disponen de la capacidad armada suficiente para mantener su ofensiva, sin lograr hacerse daños significativos que comprometan la continuidad de las pretensiones de poder entre los actores armados.

- Otro patrón muy claro identificado dentro de los periodos de ofensivas y de repliegue de los actores del conflicto ha sido la coincidencia en los periodos ofensivos y de repliegue de la Fuerza Pública y los grupos paramilitares y emergentes de estos, así como de los grupos armados sin identificar, lo que constituye una evidencia más de que la Fuerza Pública y los grupos de extrema derecha en Colombia comparten una misma estrategia territorial y de guerra, y está dirigida contra la subversión. 
- Los resultados de la investigación demuestran que los homicidios, masacres, desapariciones, secuestros y desplazamientos, principalmente, son prácticas del ejercicio de territorialidades por parte de los actores armados. El 71\% (10.023) de los homicidios registrados en estas dos últimas décadas en la región del Suroccidente colombiano sucedieron en los 30 municipios que corresponden a $\operatorname{los} 7$ territorios estratégicos identificados; igualmente, en estos se concentró el $81 \%$ (462) de las víctimas de masacres, el $98 \%$ (268) de las víctimas halladas en fosas comunes, el $65 \%$ (469) de los secuestros y el $68 \%$ (17.004) de los desplazados (expulsión) en esta región.

\section{Literatura citada}

Bozzano, H. (2000). Territorios reales, territorios pensados, territorios posibles. Buenos Aires: Espacio.

Collier, P. (2002). Greed and Grievance in Civil War. World Bank.

Echandía, C. (2006). Dos décadas de escalonamiento del conflicto armado en Colombia: 1986-2006. Bogotá. Universidad Externado de Colombia.

Jiménez R., L. C. (2009). Alternativas de desarrollo endógeno en la región periférica Surcolombiana. Bogotá: Universidad Nacional de Colombia. [Documento inédito].

McColl R., W. (1969). "The insurgent state: Territorial bases of revolution”. Annals of the Association of American Geographers, 59(4): 613-631.

Misas, G. (1991). “Apertura económica y apertura política: Dos escenarios no siempre coincidentes”. Análisis Político, N. ${ }^{\circ}$ 12. Bogotá: Universidad Nacional de Colombia.

Moncayo E., J. (2004). Las políticas regionales en Colombia. Bogotá: Universidad Externado de Colombia.

Montañez, G. et al. (1997). Geografía y ambiente: enfoques y perspectivas. Bogotá: Universidad de la Sabana. Colección Ciencias Sociales.

Montañez, G. y Delgado, O. (1998). "Espacio, territorio y región: Conceptos básicos para un proyecto nacional”. Cuadernos de Geografía, VII(12): 121-133. Bogotá:

34 Luis Gabriel Salas Salazar 
Universidad Nacional de Colombia.

Naciones Unidas. Oficina de las Naciones Unidas contra las Drogas y el Delito, Sistema de Monitoreo de Cultivos Ilícitos de Colombia -SIMCI-. (2003). Colombia, monitoreo de cultivos ilícitos: censo de cultivos de coca de 2002. Bogotá.

Naciones Unidas. Oficina de las Naciones Unidas contra las Drogas y el Delito, Sistema de Monitoreo de Cultivos Ilícitos de Colombia -SIMCI-. (2004). Colombia, monitoreo de cultivos ilícitos: censo de cultivos de coca de 2003. Bogotá.

Naciones Unidas. Oficina de las Naciones Unidas contra las Drogas y el Delito, Sistema de Monitoreo de Cultivos Ilícitos de Colombia -SIMCI-. (2009). Colombia, monitoreo de cultivos ilícitos: censo de cultivos de coca de 2010. Bogotá.

Oficina del Alto Comisionado para la Paz, Presidencia de la República de Colombia. (2007). Proceso de Paz con las Autodefensas. Disponible en: http://www.altocomisionadoparalapaz.gov.co/web/g_autodefensa/dialogos.htm [Se tuvo acceso en marzo de 2009].

Organización de Estados Americanos -OEA-. Apoyo al proceso de paz -MAPP-. (2007). Séptimo informe trimestral del secretario general al Consejo Permanente sobre la misión de apoyo al proceso de paz en Colombia. Bogotá.

Palacios, M. (1996). "La gobernabilidad en Colombia: aspectos históricos". Análisis Político, 29: 1-23. Bogotá: Universidad Nacional de Colombia.

Pécaut, D. (2004). Hacia la desterritorialidad de la guerra y la resistencia a la guerra. Red de Estudios de Espacios y Territorios, RET. Dimensiones territoriales de la guerra y la Paz. Bogotá: Unilibros, Universidad Nacional de Colombia.

Pécaut, D. (2008). Las FARC: ¿Una guerrilla sin fin o sin fines? Bogotá: Editorial Norma.

Pissoat, O. y Gouëset, V. (2002). "La representación cartográfica de la violencia en las Ciencias Sociales de Colombia”. Análisis Político, 45: 3-34. Bogotá: IepriUniversidad Nacional.

Sack, R. D. (1986). Human Territoriality: Its Theory and history. Cambridge: Cambridge University Press.

Salas L., G. (2007). "Identificación de patrones espaciales de la confrontación armada en Colombia con el método de Densidades Focales Kernel. 1998-2005”.

\begin{tabular}{l|l} 
Perspect. geogr. Vol. 15. Año 2010, pp. 9-36 & 35
\end{tabular} 
Perspectiva Geográfica, 12: 37-70. Bogotá: Universidad Pedagógica y Tecnológica de Colombia-Instituto Geográfico Agustín Codazzi.

Salas L., G. (2010). Dinámica de las territorialidades de los actores del conflicto armado en el Suroccidente colombiano: Una perspectiva geográfica, 1990-2007. Tesis de Maestría. Bogotá: Universidad Pedagógica y Tecnológica de Colombia Instituto Geográfico Agustín Codazzi.

Sánchez, F. y Chacón, M. (2002). Conflicto, Estado y descentralización: del progreso social a la disputa por el control armado. Bogotá: Centro de Estudios para el Desarrollo Económico (CEDE), Universidad de Los Andes.

Vélez, M. (2000). FARC-ELN: Evolución y expansión territorial. Tesis de pregrado. Bogotá: Facultad de Economía, Universidad de Los Andes. 